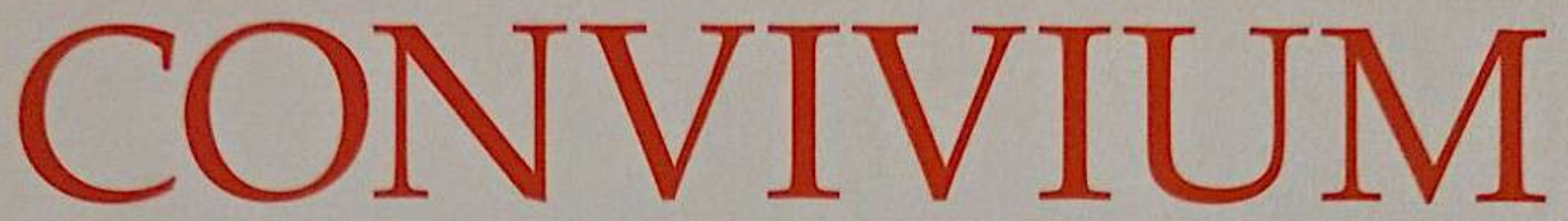

Exchanges and Interactions in the Arts of Medieval Europe, Byzantium, and the Mediterranean Seminarium Kondakovianum Series Nova
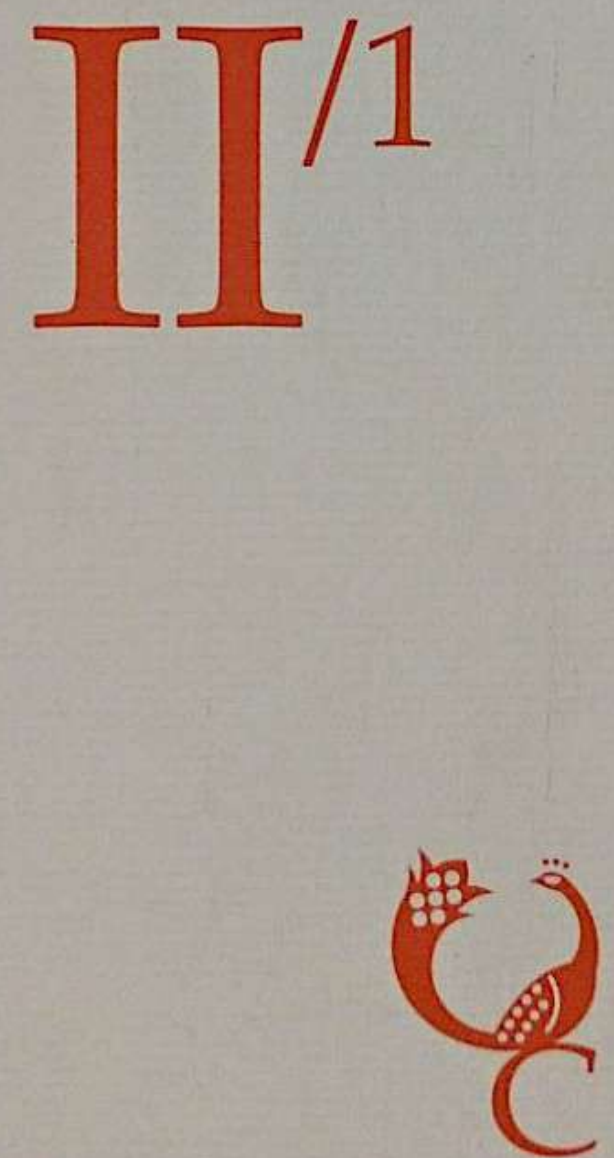


\section{CONVIVIUM II/1/2015}

Exchanges and Interactions in the Arts of Medieval Europe, Byzantium, and the Mediterranean Seminarium Kondakovianum Series Nova

Journal of the Department of Art History of the University of Lausanne, of the Department of Art History of the Masaryk University, and of the Institute of Art History of the Academy of Sciences of the Czech Republic

\section{Editor-in-chief / Ivan Foletti}

Executive editors / Karolina Foletti, Zuzana Frantová, Adrien Palladino, Pavla Tichá, Veronika

Tvrzniková, Johanna Zacharias

Typesetting / Anna Kelblová, Monika Kučerová

Cover design / Petr M. Vronský

Publisher / Masarykova univerzita, Žerotínovo nám. 9, 60177 Brno, IČ 00216224

Editorial Office / Seminář dějin uměni, Filozofická fakulta Masarykovy univerzity, Arna Nováka 1, 60200 Brno

E-mail / convivium @earlymedievalstudies.com

http://www.earlymedievalstudies.com/convivium.html

Print by / ASTRON studio CZ, a.s.; Green Park, Veselská 699, 19900 Praha 9

Published / June 2015

Reg. No. MK ČR E 21592

ISSN 2336-3452

ISBN $978-80-210-7866-6$

(9) Ústav dějin uměni AV ČR, v. v. i. 2015

(c) Filozofická fakulta Masarykovy univerzity 2015

D Faculté des Lettres, Université de Lausanne 2015 


\section{Many Romes}

Studies in Honor of Hans Belting

Edited by Ivan Foletti and Herbert L. Kessler 


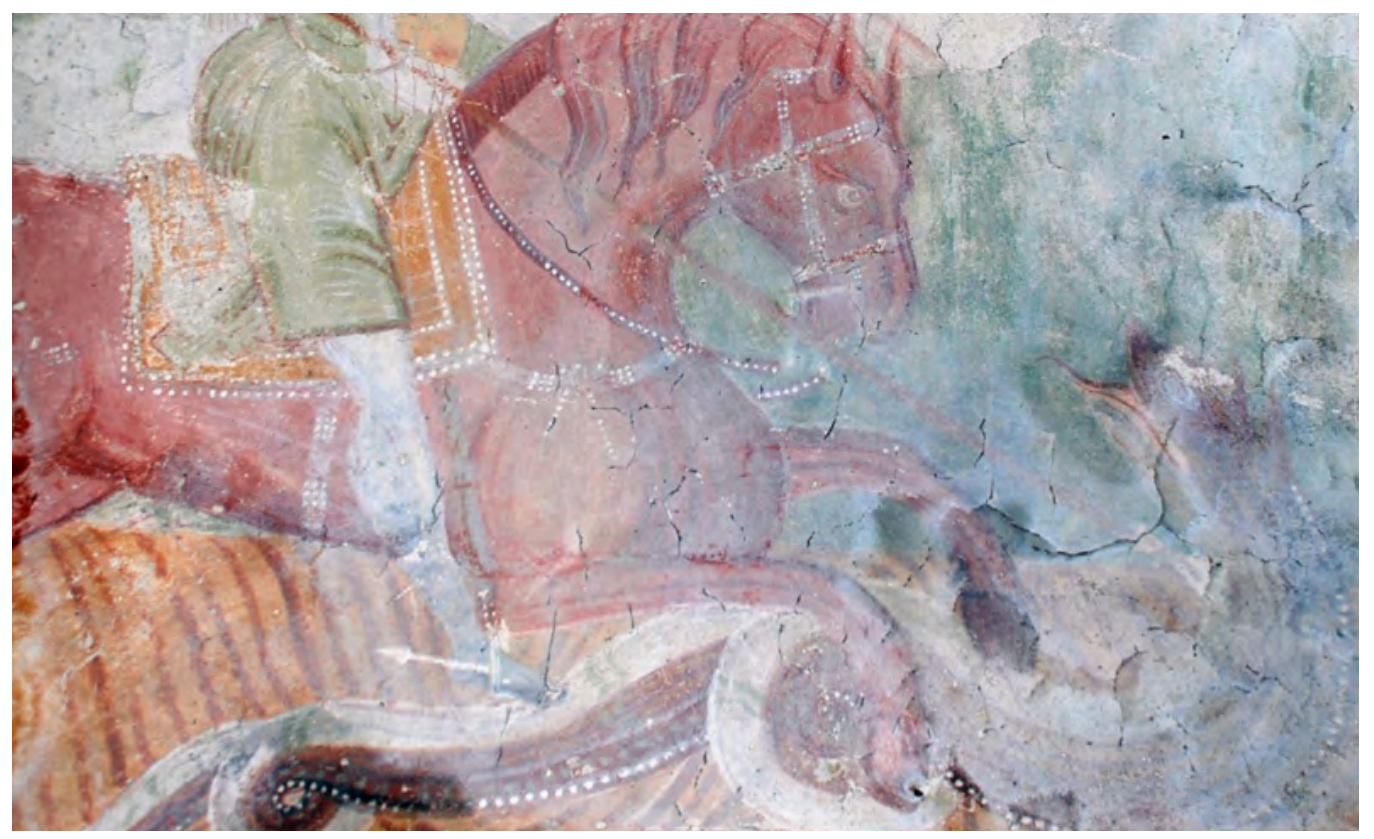

/Abstract/ Under the walls of the eighteenth-century Monte Oliveto convent in Airola, near Benevento, lies the monastic church of St Gabriel; its foundation has been dated at 960-970. Among the paintings recently discovered in the church, of particular interest is a Transfiguration in the right apse. Beyond the liturgical implications associated with its placement, the Airola version has distinctive figurative detail with strong symbolic significance. Between the apostles who attend the Vision is evidence of three tents, which refer to Peter's proposal that, in the Gospels, remains unheeded (Matthew 17, 1-8; Mark 9, 2-8; Luke 9, 28-36). This article examines the exceptional nature of this subject, which is highly significant in terms of both theology and doctrine. More generally, it also offers a formal and iconographic analysis of the paintings of St Gabriel, taking into account both the Byzantine origin of the Transfiguration and other subjects depicted (e.g., St Theodore Slaying the Dragon and St Nicholas and the Three Officers), and the stylistic language reflecting the local pictorial tradition of the ninth and tenth centuries.

/Keywords / Monastic Church of Saint Gabriel, Benedictine Art, Byzantine Art, Beneventan Painting, Saint Theodore and the Dragon, Saint Nicholas and the Three Officers, Transfiguration, Tabor Mountain.

Simone Piazza

Centre d'études médiévales de Montpellier simone.piazza@univ-montp3.fr 


\title{
Un unicum fra Oriente e Occidente \\ L'immagine della Trasfigurazione in San Gabriele ad Airola, Benevento
}

\author{
Simone Piazza
}

$E^{\prime}$ trascorso quasi mezzo secolo dall'uscita dell'illuminante libro di Hans Belting sulla beneventanischen Malere $i^{1}$, e nel frattempo la conoscenza delle pitture appartenenti all'ambito in questione, fra $\mathrm{i}$ più fecondi dell'occidente altomedievale, si è viepiù arricchita di testimonianze: numerose sono le nuove acquisizioni registrate nel campo della miniatura ${ }^{2} \mathrm{e}$ per quanto riguarda i dipinti murali ulteriori scoperte sono avvenute vuoi fortuitamente, durante lavori di restauro seguiti ad eventi sismici ${ }^{3}$, vuoi perlustrando sperduti santuari rupestri ${ }^{4}$ o sotterranei di edifici moderni ${ }^{5}$. Rientrano in quest'ultimo caso le pitture della chiesa monastica di San Gabriele ad Airola, in provincia di Benevento, nascoste al di sotto dell'imponente mole del convento settecentesco della collina di Monteoliveto, a nord della cittadina, oggi occupato da una comunità di padri passionisti ${ }^{6}$.

Notizie sull'insediamento benedettino - quasi del tutto ignorato dalla storiografia moderna - si ricavano da bolle pontificie e da una serie di antichi documenti custoditi in loco fino alle soglie del xIX secolo, smarriti a seguito della dispersione dell'ordine degli olivetani, che dal 1545 al 1788 l'avevano abitato, ma noti attraverso trascrizioni e commenti di eruditi ${ }^{7}$. In una memoria del 1201, contenuta nelle Historiae Olivetanae, vengono rievocate le leggendarie origini della chiesa primitiva: l'anno 960, sul colle soprastante l'abitato di Airola, l'arcangelo Gabriele sarebbe
1 Hans Belting, Studien zur beneventanischen Malerei, Wiesbaden 1968. 2 Giulia Orofino, "La miniatura a Benevento", in I Longobardi dei ducati di Spoleto e Benevento, Atti del xvi Congresso Internazionale di Studi sull'Alto Medioevo (Spoleto, 20-23 ottobre 2002, Benevento, 24-27 ottobre 2002), Spoleto 2003, I, pp. 545-566.

3 E' il caso delle pitture rinvenute all'interno della chiesa capuana di San Benedetto nel corso dei lavori di restauro sopraggiunti a seguito del sisma del 1980: Lucinia Speciale, Giuseppina Torriero Nardone, "Sicut nunc cernitur satis pulcherrima construxit: la basilica e gli affreschi desideriani di S. Benedetto a Capua", Arte Medievale, IX (1995), pp. 87-104. Per una proposta di anticipazione dei dipinti alla fine del $x$ secolo, cfr. Simone Piazza, "Pittura 'beneventana'? Questioni storiografiche alla luce di una nuova acquisizione: dipinti della chiesa di San Gabriele sotto il monastero di Monteoliveto ad Airola", in Medioevo: arte e storia, Atti del convegno internazionale di studi (Parma, 18-22 settembre 2007), a cura di Arturo Carlo Quintavalle, Milano 2008, pp. 367-384, sp. p. 380, nota 71a p. 383, fig. 33a p. 378.

4 Si vedano, ad esempio, le pitture dei santuari micaelici del Montemonaco di Gioia, nei pressi di Faicchio (Mario D'Onofrio, Valentino Pace, Italia romanica. La Campania, Milano 1981, p. 325; Simone Piazza, Pittura rupestre medievale. Lazio e Campania settentrionale, secoli VI-XIII, Roma 2006, sp. pp. 164-167, 234-235) e di Curti, frazione di Gioia Sannitica: Francesco Gervasio, "Insediamenti rupestri in Campania: le province di Caserta e Salerno", in Le aree rupestri dell'Italia centro-meridionale nell'ambito delle civiltà italiche, Iv Convegno Internazionale sulla Civiltà Rupestre (Savelletri di Fasano, 26-28 novembre 2009), a cura di Cosimo Damiano Fonseca, Spoleto 2011, pp. 79-120, sp. pp. 93-94.

5 Oltre ai dipinti della chiesa di Airola, oggetto del presente contributo, si possono citare - sempre a titolo di esempio - le pitture di una grotta di Castel Campagnano (provincia di Caserta) adibita a cantina di un palazzo settecentesco (Ibidem, p. 100).

6 Piazza, "Pittura 'beneventana'?" (n. 3), pp. 367-377. Sul convento settecentesco si veda: Giuseppe Rago, "Il complesso di S. Gabriele arcangelo ad Airola nel repertorio di Martino Buonocore", Palladio, xxxviII (2007), pp. 51-70.

7 Secondo Lancellotti, Historiae Olivetanae, Venezia 1623, pp. 345-349; Giuseppe Montella, Cenno storico e topografico dell'antica e moderna Airola sita nella Valle Caudina, Caserta 1848, pp. 48-53; Padre Filippo della Sacra Famiglia, Monografia della Chiesa e del Ritiro dei pr. Passionisti in Airola (Benevento), Casamari 1966, pp. 13-26; Pancrazio Scanzano, Il faro della Valle Caudina, Marigliano 1988, pp. 15-48. 


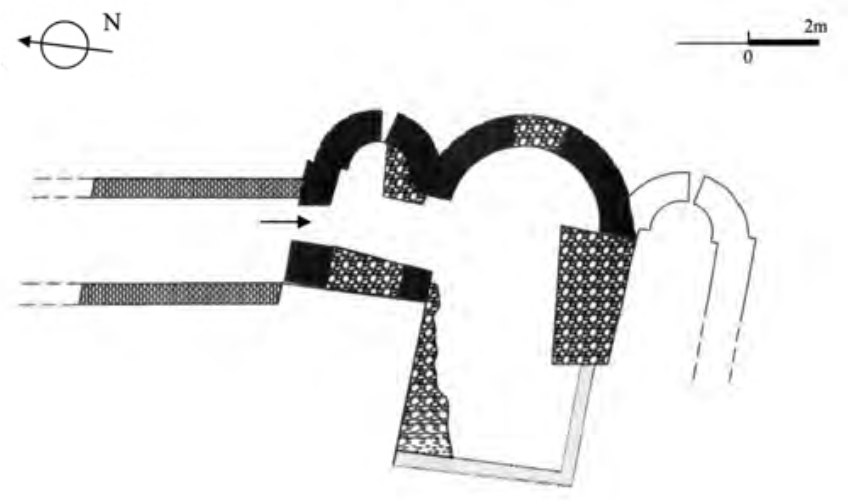

MURA DI SOSTRUZIONE (XVIII SEC.)

- muratura originaria (X-XI SEC.)

- MURA DELLE CANTINE DEL CONVENTO (XVIII SEC.)

PIETRISCO MISTO A TERRA DI RIEMPIMENTO (XVIII SEC?? IPOTESI DI SVILUPPO DELLA NAVATA DESTRA (X-XI SEC.)
1/ Ipotesi di restituzione pianta della chiesa, monastero di San Gabriele, Airola, 960-970

2/ San Teodoro e il drago, chiesa monastica di San Gabriele Airola, 960-970

3/ San Nicola intercede in favore dei tre soldati, chiesa monastica di San Gabriele, Airola, 960-970 disceso dal cielo per mettere in fuga i saraceni che stavano assediando la città e gli airolani avrebbero costruito in quel luogo un tempio in suo onore per grazia ricevuta ${ }^{8}$.

Sempre nelle Historiae Olivetanae troviamo un attento esame dei reperti medievali rinvenuti nel 1607 all'interno della chiesa di San Gabriele, in occasione dei lavori intrapresi a seguito di un cedimento strutturale dell'edificio altomedievale: in una cavità di una colonna, visibile oggi nella soprastante chiesa settecentesca, furono trovati frammenti ossei di san Bartolomeo apostolo, insieme a una pergamena con la data del 970 e il nome del donatore delle reliquie, Landolfo, primo arcivescovo di Benevento (957-984) ${ }^{9}$.

Stando alla tradizione, quindi, l'antica chiesa di San Gabriele venne costruita fra il 960 e il 970, lasso di tempo che offre un sicuro terminus post quem per la cronologia delle relative pitture, le quali, come si avrà modo di spiegare fra poco, appaiono ascrivibili entro la prima metà dell'xi secolo. Attorno al primitivo insediamento dedicato all'arcangelo, fin da subito o alcuni decenni dopo, sorse un monastero i cui resti sono stati segnalati in varie zone sotto l'attuale convento $^{10}$. In una bolla pontificia redatta a Benevento nel 1108, d'altra parte, Pasquale II conferma alcune donazioni al dilecto filio Agano ${ }^{11}$, abate del monastero di San Gabriele ${ }^{12}$, e in seguito beatificato, come risulta dai martirologi benedettini ${ }^{13}$, per aver liberato gli airolani dall'incubo della peste, sempre grazie al provvidenziale intervento dell'arcangelo interceduto dal cielo una seconda volta ${ }^{14}$. Da un'altra bolla pontificia, emanata nel 1135 da Innocenzo II, veniamo a sapere che il monastero afferiva alla giurisdizione della diocesi della vicina Sant'Agata dei Goti ${ }^{15}$.

Passate in rassegna le fonti, rivolgiamo lo sguardo alle evidenze monumentali. Nella primavera del 2007 , in occasione di un sopralluogo ${ }^{16}$, mi è stato concesso di esplorare la parte della chiesa monastica connessa alle cantine del convento: un lungo corridoio di recente costruzione immette direttamente nella navata sinistra dell'antico edificio ecclesiastico, i cui muri in alcuni punti si conservano per tutto l'alzato, volta compresa. Si tratta di un piccolo edificio triabsidato con navatelle laterali coperte da imbotte, a differenza forse dell'aula centrale forse in origine sormontata da un tetto a capriate /Fig. 1/.

Il primo ambiente che si offre allo sguardo del visitatore è la zona presbiteriale della navata sinistra, 
di cui si conservano l'absidiola, il tratto iniziale delle mura contigue e parte della volta. Sopra l'arco comunicante con la navata centrale sopravvive un'ampia porzione d'intonaco che raffigura un san Teodoro, ormai acefalo, intento ad uccidere il drago in sella ad un cavallo rosso, immagine in linea con la tradizione iconografica di origine greca /Fig. $2 /{ }^{17}$. Sul muro di fronte, nel segmento di parete che fa angolo con il vano absidale, sotto i lacerti di un riquadro ospitante forse l'episodio della Pentecoste ${ }^{18}$, è dipinta un'altra figura di matrice bizantina: un santo vescovo sul punto di bloccare a mani nude la spada sguainata da uno sgherro, soggetto certamente identificabile con l'episodio della vita di san Nicola in cui il vescovo di Mira interviene in favore di tre generali (stratelatis) ingiustamente condannati a morte / Fig. 3/ ${ }^{19}$.

Nella vicina absidiola, parzialmente occupata dalle sostruzioni del convento soprastante, quanto rimane della decorazione pittorica consente di stabilire l'originaria presenza di una triade di figure disposta attorno ad una piccola finestra rettangolare ubicata nella zona centrale, verosimilmente coeva alla fase di

8 Dell'originale del documento duecentesco s'è persa traccia: l'ultima notizia risale al 1807, allorquando il codice venne portato a Napoli dal padre olivetano Raimondo Grimaldi: Montella, Cenno storico (n. 7), pp. 45-47, sp. nota 45. Il testo si trova in Lancellotti, Historiae (n. 7), p. 347. Una sua traduzione italiana è contenuta in un atto di supplica del 1608: cfr. Giuseppe Montella, Osservazioni sul cenno storico, e topografico dell'antica, e moderna Airola, Napoli 1851, p. 10; Scanzano, Il faro (n. 7), pp. 35-36, 61-62.

9 Lancellotti, Historiae (n. 7), p. 347; Montella, Cenno storico (n. 7), p. 49.

10 Filippo della Sacra Famiglia, Monografia (n. 7), pp. 15-17.

11 Paul Fridolin Kehr, Papsturkunden in Italien: Reiseberichte zur Italia pontificia, Città del Vaticano 1977, v, pp. 209-210. La bolla riporta anche la notizia di una donazione al monastero airolano da parte di Rainolfo conte di Alife, Telese ed Airola (1066-1087) e sua moglie Sibilla: cfr. Herbert Bloch, Monte Cassino in the Middle Ages, Roma 1986, I, p. 262.

12 Le spoglie dell'abate Agano sarebbero state trovate nel corso dei lavori nell'antica chiesa di Airola, nel corso degli anni 1607-1608: Scanzano, Il faro (n. 7), pp. 32-36; Rago, "Il complesso di S. Gabriele" (n. 6), pp. 52,54 .

13 Gabriel Bucelinus, Menologium benedictinum sanctorum, beatorum atque illustrium eiusdem ordinis virorum elogiis illustratum, Augusta 1656, p. 128. Cfr. Alfonso M. Zimmermann, s.v. "Agano", Bibliotheca Sanctorum, I, Roma 1961, col. 299.

14 L'episodio era contenuto in un documento del 1199, rinvenuto nel corso dei lavori intrapresi all'interno dell'antica chiesa di Airola nel 1608 , perduto anch'esso, ma trascritto integralmente in Lancellotti, Historiae (n. 7), p. 348

15 Kehr, Papsturkunden (n. 11), v, pp. 211-212.

16 Piazza, "Pittura 'beneventana'?" (n. 3), p. 367

17 Nell'iconografia bizantina il cavallo di Teodoro è rosso per distinguerlo da quello di san Giorgio di colore bianco: Günter Paulus Schiemenz, "Herr, hilf deinem Knecht. Zur Frage nimbierter Stifter in den kappadokischen Höhlenkirche", Römische Quartalschrift, LxxI/3-4 (1976), pp. 133-174, sp. p. 162.

18 Piazza, "Pittura 'beneventana'?" (n. 3), p. 369 e fig. 22.

19 Sulla diffusione dell'episodio agiografico nell'arte bizantina e le fonti dal quale è tratto, cfr: Nancy Patterson Ševčenko, The life of Saint Nicholas in Byzantine art, Torino 1983, pp. 104-108.
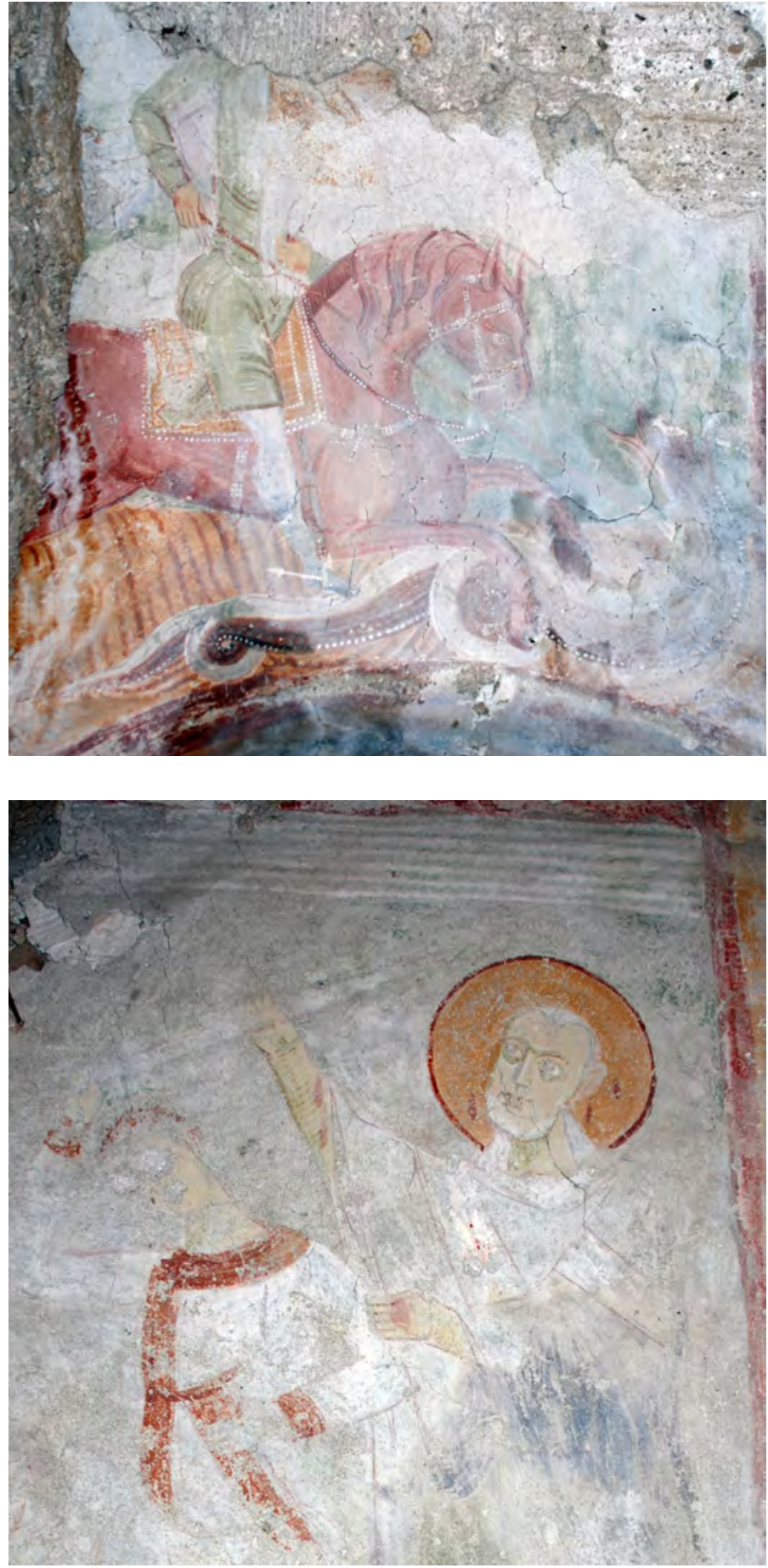


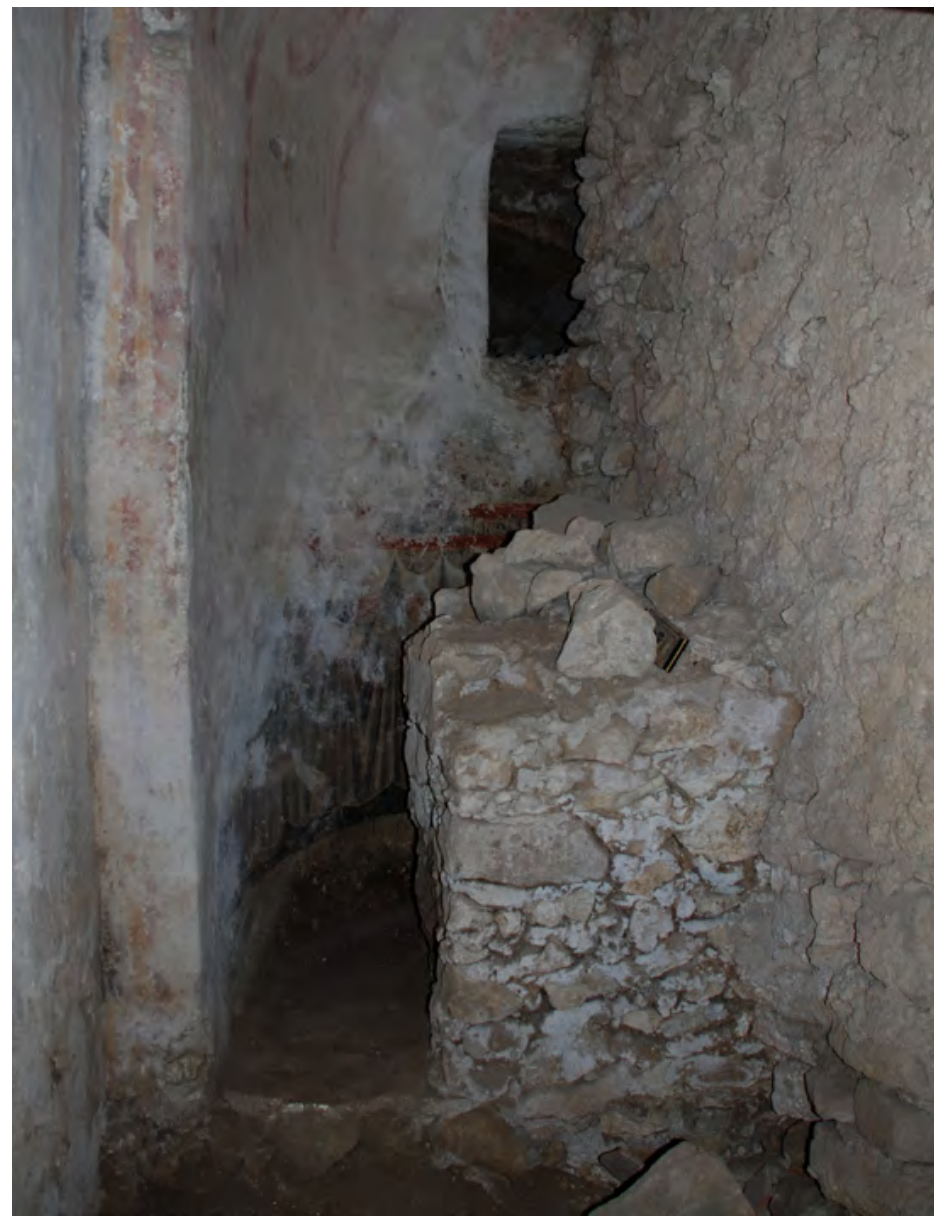

costruzione /Fig. 4/. Sopra al lucernario si scorgono labili tracce del busto di Cristo con aureola crucesignata raffigurato nell'atto di benedire. In quel che resta del personaggio di sinistra s'intravedono i segni caratteristici del Battista, rivolto di tre quarti verso il Messia, il mantello aperto sul davanti, la barba e i capelli lunghi, la mano sinistra alzata ad esibire un cartiglio. Faceva forse pendant a destra, sul tratto di parete coperto dalla muratura moderna, l'immagine di Giovanni Evangelista: frequente è infatti l'iconografica dei due Giovanni reggenti un filatterio con versetti evangelici accanto al Cristo in trono ${ }^{20}$.

Per quanto riguarda la zona inferiore del piccolo emiciclo, dietro un altare a blocco ancora assai ben conservato, si distinguono nitidamente i resti di un velarium, sormontato da un'iscrizione facente riferimento ad un'orazione liturgica ${ }^{21}$. Al di sopra della calotta, invece, lungo la cornice dell'arco, labili tracce di colore restituiscono il dispiegarsi di un'alta fascia a motivi geometrici con al centro un medaglione racchiudente una dextera Domini.

Della decorazione della navata centrale restano avanzi significativi in corrispondenza dell'abside. Quest'ultima, incorniciata ai due lati da un nastro geometrico che scaturisce da un vaso appoggiato ad una colonna, ospita i resti di sette personaggi in posa frontale /Fig. 5/. Da sinistra verso destra, si riescono a scorgere un santo che regge una pisside, una figura vestita di bianco, un arcangelo con loros, una Vergine in trono, riconoscibile dal cuscino purpureo ma anche dalle tracce del manto, un secondo arcangelo ${ }^{22}$, un santo con tunica ocra e manto rosso e infine un'orante. Al di sotto della teoria di personaggi a figura intera corrono sei medaglioni annodati con santi a mezzo busto. Soltanto uno fra questi s'è parzialmente conservato e sembrerebbe riprodurre sembianze femminilii ${ }^{23}$.

Il percorso fra gli antichi resti della chiesa monastica, collegato alle cantine del convento di Monteoliveto, non consente di procedere oltre: le fondamenta dell'edificio soprastante bloccano il passaggio alla navata destra. Quest'ultima sarebbe ispezionabile sollevando una botola del giardino antistante l'edificio conventuale, che però è stata resa inamovibile. Durante un'ulteriore visita ad Airola, avvenuta nella primavera del 2008, allorquando erano in corso lavori di ristrutturazione del convento, la temporanea rimozione della lastra di cemento mi ha offerto 
l'opportunità di scendere nell'ambiente sottostante ${ }^{24}$. Ho quindi potuto documentare i temi figurativi rimasti fino ad allora inaccessibili: una monumentale Trasfigurazione, aderente alla superficie del catino absidale (Figg. 6-7), e alcuni soggetti della parete circostante, questi ultimi distinguibili soltanto di scorcio data l'esiguità dello spazio che separa le murature antiche da quelle moderne. Per via delle interessanti implicazioni simboliche derivanti dalla sua posizione all'interno della conca absidale e soprattutto a causa dell'assoluta originalità di certi suoi elementi iconografici, la scena teofanica airolese merita una trattazione particolareggiata ${ }^{25}$.

Per quanto riguarda l'ubicazione, trovare la Trasfigurazione all'interno di un'abside si rivela una circostanza piuttosto insolita, tanto in ambito latino che in Oriente. In area bizantina, oltre al celebre mosaico del Sinai (vi secolo) ${ }^{26}$, si registrano soltanto un paio di casi nell'ambito della pittura rupestre della Cappadocia, all'interno della chiesa di San Giovanni Battista di Çavuşin (vII-vIII secolo) e di San Giorgio

20 Piazza, Pittura rupestre medievale (n. 4), p. 84 e nota

21 Vi si legge: OM(NI)P(O)T(EN)S ET SE[MPITERNE DEUS], formula frequentissima nelle orazioni liturgiche.

22 Simmetrico a quello di sinistra, secondo una prassi antica che consente di associare i due arcangeli alla coppia Michele-Gabriele.

23 Il motivo dei cerchi annodati con personaggi a mezzo busto è attestato in altre chiese monastiche benedettine, come modulo figurativo impiegato per presentare i ritratti degli abati: si vedano i casi di San Benedetto a Capua (Cfr. Speciale/Torriero Nardone, "Sicut nunc cernitur", [n. 3], pp. 96-97, fig. 10) e di San Magno a Fondi, le cui pitture, ancora inedite, sono venute alla luce di recente, cfr. Il monastero di San Magno a Fondi, a cura di Nicoletta Cassieri, Vincenzo Fiocchi Nicolai, Tivoli 2013.

24 Del sopralluogo si è data notizia in occasione di un recente convegno: Simone Piazza, "La pittura di area beneventano-cassinese e l'orbita bizantina", L'Héritage byzantin en Italie (vIII ${ }^{e}-\mathrm{XII}{ }^{e}$ siècle). v. Décor Monumental, Objets, Tradition Textuelle. Journées d'étude, Rome, 25-26 Novembre 2011, a cura di Jean-Marie Martin, Sulamith Brodbeck, Roma, in corso di stampa. Desidero esprimere la mia più viva riconoscenza ai padri passionisti del convento di Monteoliveto, che con grande disponibilità sono venuti incontro ad ogni mia esigenza legata allo studio del monumento. Il mio pensiero va, in particolare, al compianto padre Pancrazio Scanzano, custode della memoria storica del monastero airolano, al quale devo la mia gratitudine per i preziosi consigli e per essersi adoperato in favore dell'accesso alla navata destra della chiesa di San Gabriele.

25 Per uno sguardo generale sull'iconografia della Trasfigurazione, cfr. Friedrich Gerke, "La 'metamorfosi' nell'arte protobizantina", Corso di Cultura sull'Arte Ravennate e Bizantina, vir/2 (1960), pp. 99-109; Josef Myslivec, "Verklärung Christi", Lexikon der Christlichen Ikonographie, IV, Roma/Friburgo/Basilea/Vienna 1972, coll. 416-421; Suzy Dufrenne, "La manifestation divine dans l'iconographie byzantine de la Transfiguration", in Nicée II, 787-1987: douze siècles d'images religieuses, Colloque International Nicée Deux, Parigi 1986, pp. 185-206; Alfons Wohlgemuth, "Das Fest der Verklärung Christi in der frühchristlichen und byzantinischen Kunst", Hermeneia, xvi/1 (2000), pp. 15-28; Maria Kapp, “Die Verklärung Christi", Weltkunst: Zeitschrift für Kunst und Antiquitäten, LXXvi/1 (2006), p. 38.

26 Andreas Andreopoulos, "The mosaic of the transfiguration in St. Catherine's Monastery on Mount Sinai: a discussion of its origins", Byzantion, LXxII/1 (2002), pp. 9-41; Jerzy Miziołek, "I mosaici della basilica del Monte Sinai: nuove osservazioni sulle fonti delle raffigurazioni e del loro contenuto ideale", Arte cristiana, xcIv (2006), pp. 399-408.

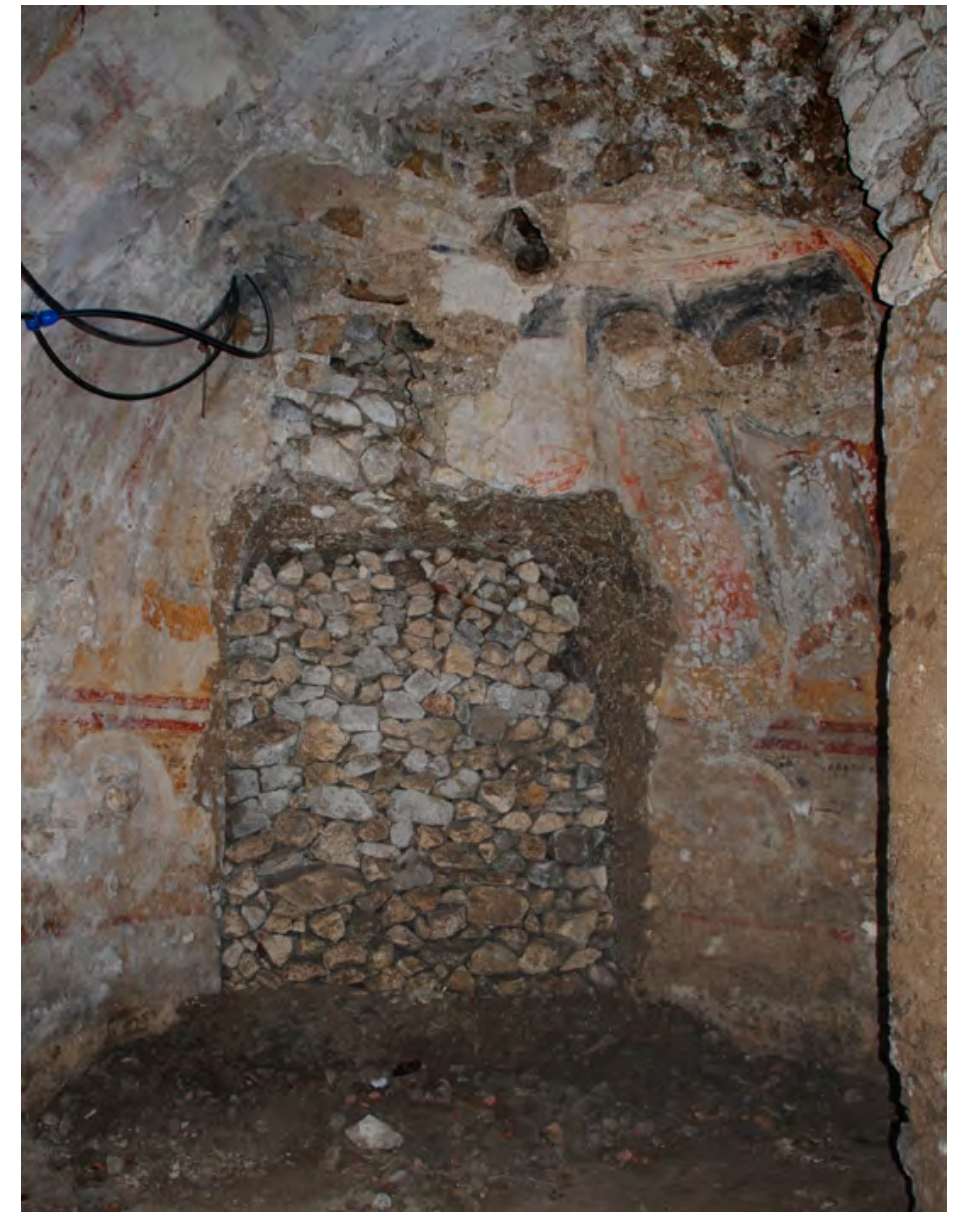

4/ Abside sinistra, chiesa monastica di San Gabriele, Airola, 960-970

5/Abside centrale, chiesa monastica di San Gabriele, Airola, 960-970 

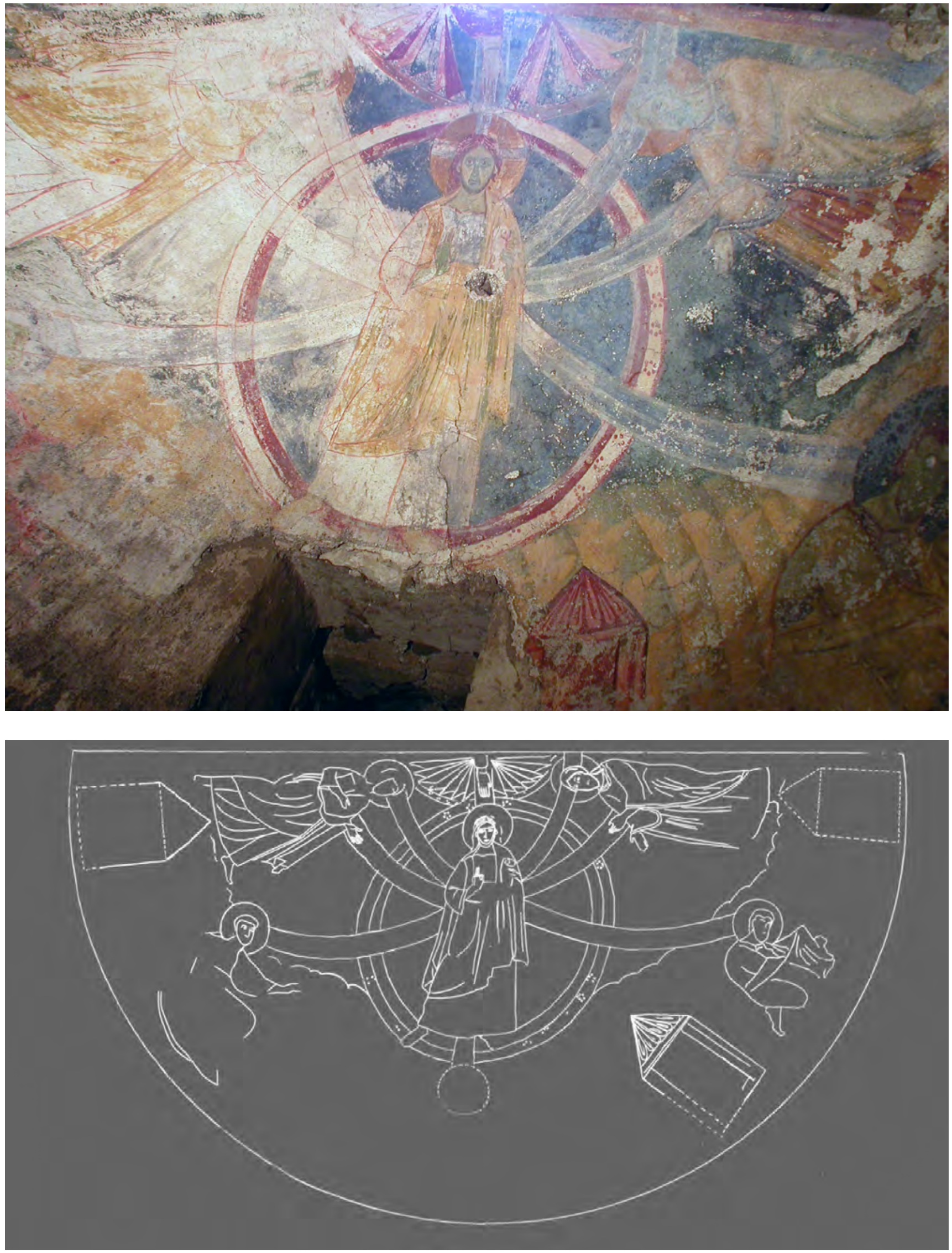
presso Gülşehir (xI secolo) ${ }^{27}$. In Occidente, a parte l'opera sui generis di Sant' Apollinare in Classe (vi secolo $)^{28}$, sono noti solo due altri esempi, entrambi altomedievali ed anch'essi campani: il mosaico eseguito al tempo del vescovo Giovanni II (533-555) nell'abside dell'antica cattedrale napoletana, perduto forse già nel ix secolo ma documentato dal Chronicon episcoporum Sanctae Napolitanae Ecclesiae ${ }^{29}$, e il rivestimento pittorico assai lacunoso di un'absidiola della chiesa di Santa Maria Assunta a Pernosano, nell'avellinese, che dati documentari consentirebbero di datare agli inizi del $x$ secolo $^{30}$. In tutte le versioni citate, la scelta di collocare la Trasfigurazione nel catino absidale è dovuta al valore metastorico della teofania celeste. In essa, fra l'altro, è stato colto un messaggio messianico, evocante la seconda venuta di Cristo ${ }^{31}$, che assume particolare risonanza all'interno di uno spazio a forte connotazione liturgica, ad Airola coincidente con il diaconicon delle chiese byzantine ${ }^{32}$.

Dal punto di vista iconografico, la scena dipinta ad Airola, pur riferendosi in modo esplicito all'episodio raccontato dai tre sinottici ${ }^{33}$, non appare conforme alla narrazione evangelica, come si evince da una lettura dell'insieme delle sue componenti figurative. Al centro del catino campeggia solenne la figura del Cristo, inscritto in un cerchio azzurro profilato da un bordo bicromo, vestito di una tunica bianca e pallio giallo-ocra, la mano destra benedicente, la sinistra nell'atto di impugnare il rotolo della legge, i tratti del viso accentuati da un forte chiaro-scuro dovuto al bagliore della luce divi$\mathrm{na}^{34}$. Dalla sagoma del Messia si dipartono sette fasci

27 Catherine Jolivet-Lévy, Les églises byzantines de Cappadoce: le programme iconographique de l'abside et de ses abords, Parigi 1991, pp. 24-25, 226-227.

28 Christine Milner, "The role of the prophet Elijah in the transfiguration mosaics at Sinai and Classe", in Conformity and non-conformity in Byzantium, a cura di Lynda Garland, Amsterdam 1997, pp. 207-217; Silvana Casartelli Novelli, “La 'Trasfigurazione' alla metà del vi secolo in Sant'Apollinare in Classe e a Santa Caterina al Sinai", in Le vie del medioevo, Atti del convegno internazionale di studi (Parma, 28 settembre - 1 ottobre 1998), a cura di Arturo Carlo Quintavalle, Milano 2000, pp. 63-72.

29 Ludovico Antonio Muratori, Rerum Italicarum Scriptores, Milano, I, 2, 1725, p. 298. Cfr. Vinni Lucherini, La cattedrale di Napoli: storia, architettura, storiografia di un monumento medievale, Roma 2009, pp. 110-111, 161, 163 e p. 310 per la pubblicazione in appendice della fonte.

30 Sandra Suatoni, "Pittura monumentale della Campania longobarda: gli esempi di Occiano e Pernosano", Apollo, LxviII (2001), pp. 10-45, sp. p. 16 e fig. 22, p. 24.

31 Dufrenne, "La manifestation divine" (n. 25), p. 189; Milner, "The role of the prophet Elijah" (n. 28), pp. 20-217.

32 Rudolf Egger, s.v. "Diakonikon", Reallexikon zur deutschen Kunstgeschichte, III, Stoccarda 1954, coll. 1382-1387.

33 Mt 17, 1-8; Mc 9, 2-8; Lc 9, 28-36.

34 "E fu trasfigurato davanti a loro; il suo volto brillò come il sole e le sue vesti divennero candide come la luce", Mt 17, 2.

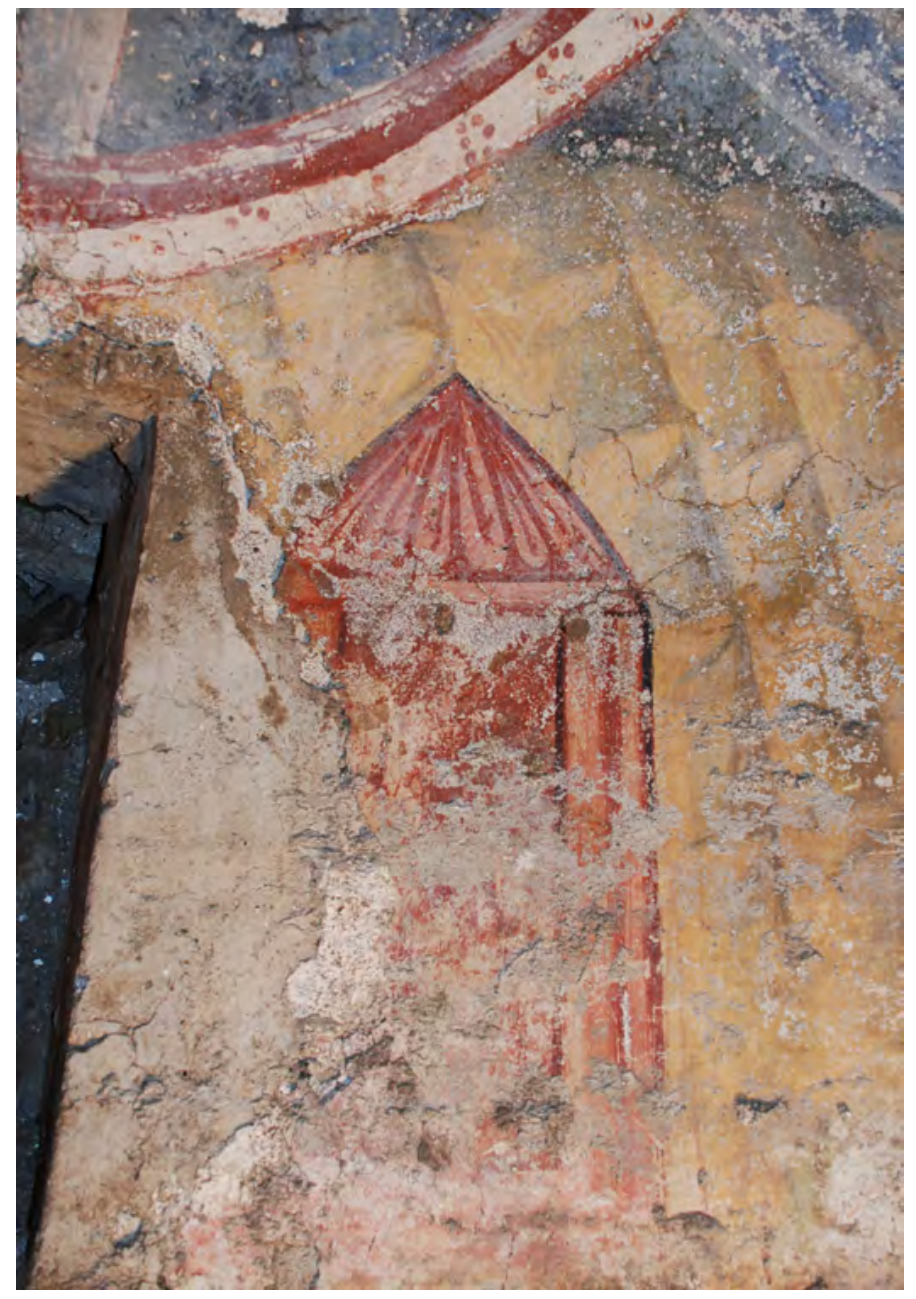

6/Abside destra: la Trasfigurazione, chiesa
monastica di San Gabriele, Airola, $960-970$

7/ Restituzione grafica della Trasfigurazione, chiesa monastica di San Gabriele, Airola, 960-970

8/Trasfigurazione, particolare di una tenda, chiesa monastica di San Gabriele, Airola, 960-970 

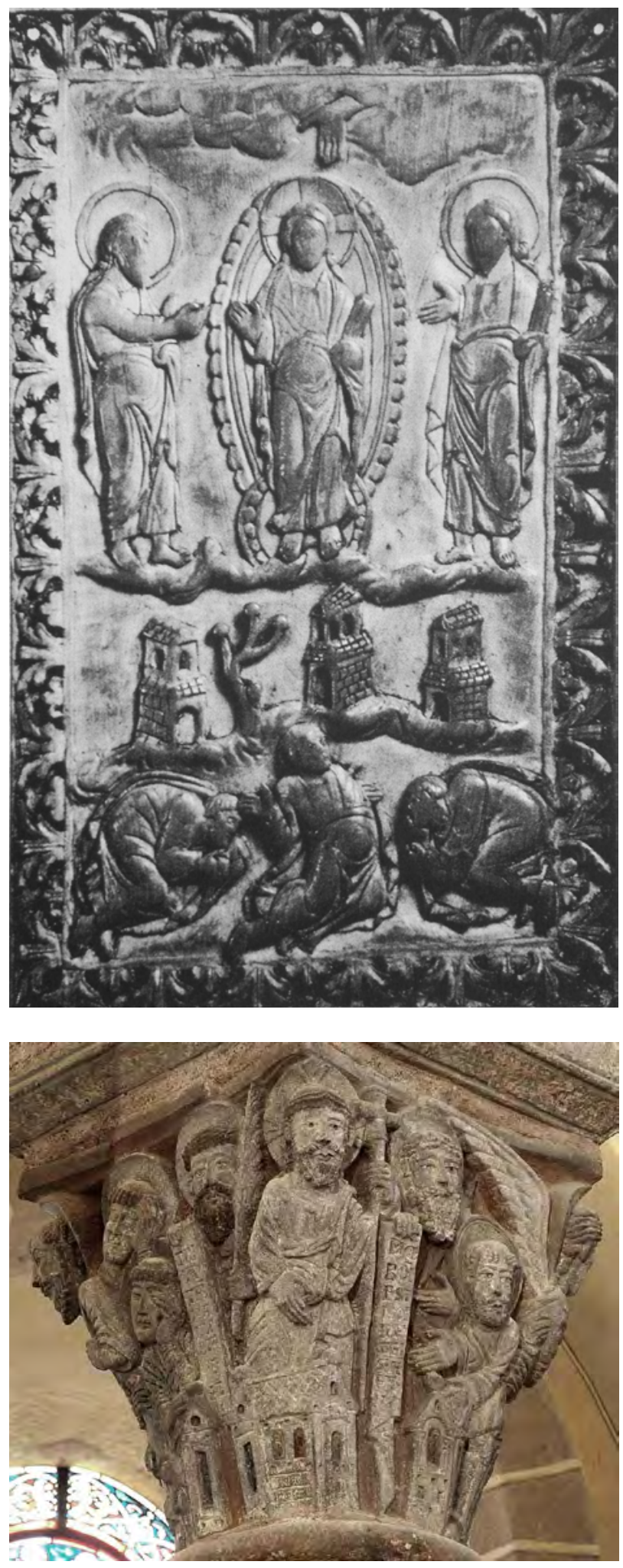

luminosi: quello centrale, in alto, collega la testa del Figlio alla mano divina proveniente da un motivo ad ombrello in forma di semicerchio evocante l'empireo; delle restanti bande luminose, disposte simmetricamente ai lati del Cristo, le due superiori e le mediane raggiungono i profeti coprotagonisti della visione, Mosè a sinistra ed Elia a destra, quelle inferiori sono invece dirette verso gli apostoli giunti al seguito di Gesù "sull'alto monte" (Mt 17,1; Mc 9, 2), tradizionalmente associato al Tabor ${ }^{35}$. Sono ancora riconoscibili le due figure laterali, Pietro a sinistra e Giacomo il Maggiore a destra, mentre l'immagine centrale di Giovanni è andata perduta a causa della caduta della pellicola pittorica. In modo assai convenzionale, ma efficace, la montagna sacra è evocata da un fitto susseguirsi di piccole balze giallo-ocra ad andamento verticale, che riflettono il chiarore divino mediante un geometrico alternarsi di luci ed ombre. Ed ecco che, sull'uniforme paesaggio si scorge del tutto inaspettatamente, in primo piano, accanto alla figura di Giacomo, una capanna rossa con tetto cuspidato /Fig. 8/. Tracce dello stesso motivo si distinguono nell'angolo inferiore sinistro della decorazione absidale. Si tratta, sorprendentemente, di un'allusione alle parole pronunciate da Pietro alla vista dei due profeti e del Cristo trasfigurato: "Signore, è bello per noi restare qui; se vuoi, farò tre tende, una per te, una per Mosé, una per Elia" (Mt 17, 4; Mc 9, 5; Lc 9, 33).

$\mathrm{E}^{\prime}$ chiaro, quindi, che nell'abside airolana, in corrispondenza dell'angolo destro, laddove oggi appare una lacuna, originariamente doveva figurare la terza tenda. Tale scelta iconografica appare davvero eccezionale dal momento che, secondo l'interpretazione esegetica, la proposta di erigere le tende rivolta da Pietro al Maestro rimane inascoltata, a significare l'incomprensione umana di fronte alla visione ultrasensibile del divino ${ }^{36}$. Una spiegazione di questa originalissima rappresentazione potrebbe risiedere nell'intenzione di voler evocare non il materializzarsi del messaggio petrino bensì l'effettiva esistenza sul monte Tabor di tre basiliche, edificate in età paleocristiana nei luoghi in cui l'apostolo avrebbe voluto erigere le tende per Gesù e i due profeti $^{37}$. Sappiamo che i santuari della montagna sacra divennero fin da subito meta incessante di pellegrinaggio e che almeno a partire dal $1101 \mathrm{sul}$ Tabor si stabilì una comunità di benedettini ${ }^{38}$. 
Ai tre luoghi di culto della Terra Santa allude un numero ristretto di immagini della Trasfigurazione che si discostano dal modello canonico: la versione più antica è quella di un avorio carolingio appartenente al cosiddetto gruppo di Liutardo, databile alla seconda metà del Ix secolo (Londra, Victoria and Albert Museum, $\mathrm{n}^{\circ}$ 253.67) ${ }^{39}$ : in esso si scorgono distintamente tre edifici ecclesiastici in muratura e tetti spioventi /Fig. $9 /{ }^{40}$. Fra xI e xII secolo il dettaglio riaffiorerà nella scultura romanica d'oltralpe: l'esempio più limpido è rappresentato dal capitello della chiesa di Saint-Nectaire, nell' Auvergne, databile agli anni 1160-1170, ove ai piedi dei protagonisti della scena evangelica compaiono di nuovo le tre chiese /Fig. 10/41. E' assai probabile che ai medesimi santuari si riferiscano gli edifici presenti nelle scene riprodotte su due altri capitelli, uno appartenente al primo atelier operante nel chiostro della Daurade di Tolosa (1100-1115) ${ }^{42}$, l'altro a quello di Moissac (ca. 1100) ${ }^{43}$. In entrambi i casi si è supposto che le costruzioni rappresentino Gerusalemme, verso la quale Cristo e gli apostoli si sarebbero diretti una volta discesi dal monte ${ }^{44}$. L'ipotesi tuttavia appare assai arbitraria, dal momento che la città santa non è menzionata nel passo evangelico in questione. $\mathrm{Ri}$ guardo al capitello della Daurade, la presenza di tre edifici, in origine sormontati da croci, non sembra lasciare dubbi circa la volontà di far riferimento ai

35 Pierre Maraval, Les Lieux saints et les pèlerinages d'Orient, Parigi 1985, pp. 292-293.

36 Dufrenne, "La manifestation divine" (n. 25), p. 189.

37 Maraval, Les Lieux saints (n. 35), p. 292.

38 Barnabé Meistermann, Le mont Thabor : notices historiques et descriptives, Parigi 1900, pp. 58-86; Maraval, Les Lieux saints (n. 35), p. 293.

39 Adolph Goldschmidt, Die Elfenbeinskulpturen aus der Zeit der Karolingischen und Sächsischen Kaiser, VIII.-XI. Jahrhundert, I, Berlino/Oxford 1969, p. 36, tav. xxviII, fig. 69.

40 Cfr. Émile Mâle, L'art religieux du XII siècle en France :étude sur les origines de l'iconographie du Moyen Âge, Parigi 1928, p. 119

41 Ibidem, p. 119, n. 1; Zygmunt Swiechowksy, Sculpture romane d'Auvergne, Clermont-Ferrand 1973, p. 80

42 Mâle, L'art religieux (n. 40), p. 119; Marie Lafargue, "Les sculptures du premier atelier de la Daurade et les chapiteaux du cloître de Moissac", Bulletin monumental, xCvir (1938), pp. 195-216, sp. pp. 201-202; Eadem, Les chapiteaux du cloitre de Notre-Dame de la Daurade, Parigi 1940, pp. 28-30, tav. v, figg. 3-4

43 Mâle, L'art religieux (n. 40), p. 119; Lafargue, "Les sculptures du premier atelier" (n. 42), pp. 202-204; Eadem, Les chapiteaux du cloitre (n. 42), p. 29; Quitterie Cazes, Maurice Scellès, Le cloître de Moissac, Bordeaux 2001, pp. 132-133.

44 A differenza dei capitelli di Saint-Nectaire e della Daurade, quello di Moissac articola il tema della Trasfigurazione in due momenti distinti: oltre al solenne evento teofanico vi è infatti una scena secondaria, in passato interpretata come momento successivo alla visione, ovvero la discesa dalla montagna (Mâle, L'art religieux [n. 40], p. 119; Lafargue, "Les sculptures du premier atelier" [n. 42], p. 203; Cazes/Scellès, Le cloitre de Moissac [n. 43], p. 132) ma forse identificabile con l'episodio precedente, cioè quello dell'ascesa al Tabor (Mt 17, 1; Mc 9, 2; Lc 9, 28).

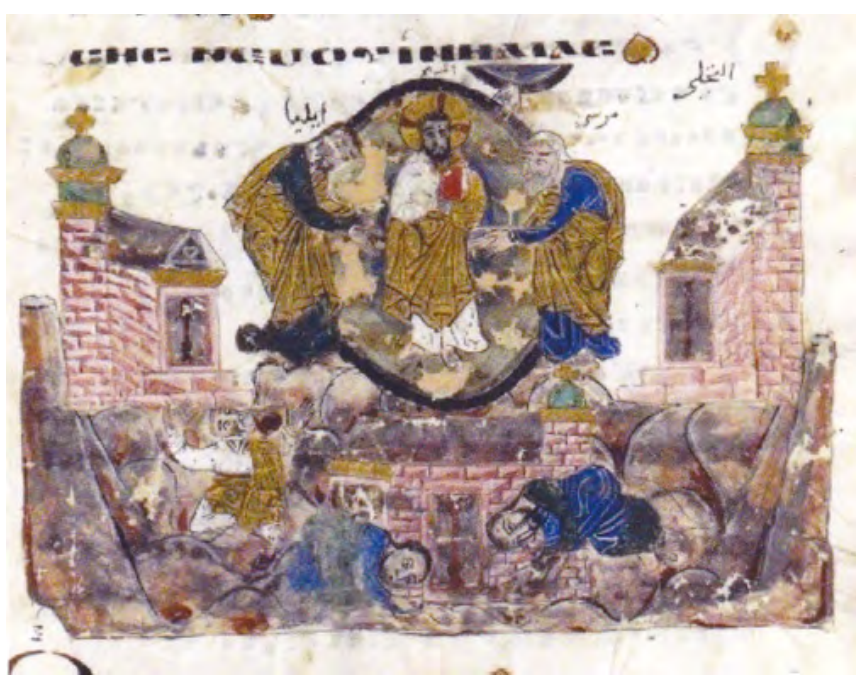

9/Avorio con Trasfigurazione,

Victoria and Albert Museum inv. n²53.67, Londra, seconda metà del Ix secolo

10/ Capitella con Trasfigurazione, église de SaintNectaire, Saint-Nectaire (Auvergne), 1160-1170

11/ La Trasfigurazione in un manoscritto copto, Parigi, bnf, Copte 13, fol. 48, Bibliothèque Nationale de France, Paris, 1179-1180 
12/ Trasfigurazione, mosaico, monastero

della Nea Moni, Chio, ca. 1040

13/ Restituzione grafica delle absidi, Grotta dell'Angelo, Olevano sul Tusciano, seconda metà del x secolo o primi anni dell'xI secolo

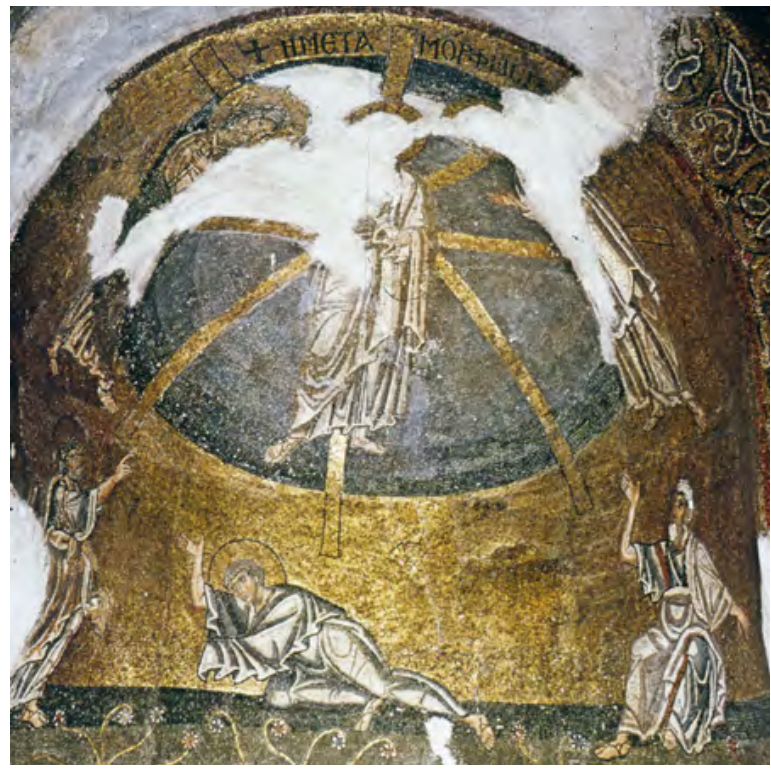

luoghi di culto sorti sul monte della Trasfigurazione. Quanto alla versione riprodotta nel chiostro di Moissac, la rappresentazione di un'unica monumentale architettura che ospita al suo interno tre strutture turrite ben distinte, potrebbe alludere alla fortezza innalzata nel vir secolo a protezione della sommità del Tabor, includente i santuari ${ }^{45}$. Questi ultimi figurano anche in un manoscritto copto (Parigi, BNF, Copte 13, fol. 48), realizzato negli anni 1179-1180: si tratta dell'unico caso attestato nel versante orientale del Mediterraneo, iconograficamente estraneo, tuttavia, all'orbita bizantina / Fig. 11/46.

Rispetto agli esempi sopra menzionati, quello di Airola appare ancor più singolare: nell'abside della chiesa di San Gabriele, infatti, è evidente la volontà di rappresentare non un edificio architettonico, bensì una piccola tenda a padiglione, simile ai tabernacoli dell'antico testamento ${ }^{47}$. Come s'è detto manca qualsiasi argomentazione di carattere teologico-dottrinario che possa giustificare la rappresentazione delle tre tende evocate nel versetto petrino. Dalla sfera cultuale, tuttavia, si evince un dato estremamente significativo: fra le reliquie custodite nell'abbaziale di Saint-Riquier (Centula), infatti, la cronaca del monastero, risalente al xII secolo, menziona quelle "de monte ubi [Christus] transfiguratus est", compresi i resti "de lignis trium tabernaculorum" ${ }^{\prime 48}$.

$\mathrm{Al}$ di là delle tende e di qualche altro elemento figurativo, l'assetto iconografico della Trasfigurazio- radice greco-orientale. Per intercettare le tangenze con le versioni bizantine più o meno coeve, conviene accostare l'opera campana a quella del monastero della Nea Moni dell'isola di Chio (anni ' 40 dell'xI secolo) ${ }^{49}$ : analogo, infatti, è lo schema di base della composizione, con l'aureola di luce e i raggi lumino$\mathrm{si}$ - per altro di antica origine come attesta il celebre mosaico del Sinai-, ed identico è il gesto dell'adlocutio compiuto da Pietro, con il braccio destro alzato e l'indice puntato verso il Cristo, ad evocare la frase pronunciata al cospetto della visione /Fig. 12/.

Anche per quanto riguarda il san Teodoro e il Miracolo di San Nicola, come già detto evidenti sono i richiami a matrici iconografiche di origine orientale. Tuttavia in ambedue questi casi, come in quello della Trasfigurazione, non si tratta dell'imitazione diretta di immagini greche, ma del riemergere di queste ultime da un linguaggio figurativo autoctono, la cui cifra stilistica è chiaramente latina. Dal punto di vista iconografico, del resto, l'elemento delle tende non è il solo a discostarsi dalle versioni diffuse a Bisanzio. Il particolare modo di rappresentare il paesaggio, artificiale e al tempo stesso di grande effetto, non ha eguali nelle immagini della Trasfigurazione in circolazione nel versante orientale del Mediterraneo. Né in generale trova riscontro, in area greca, la presenza sommitale della mano divina ${ }^{50}$.

Riguardo all'impianto generale del programma pittorico airolese, i confronti più significativi rimandano alla decorazione della chiesa rupestre di 

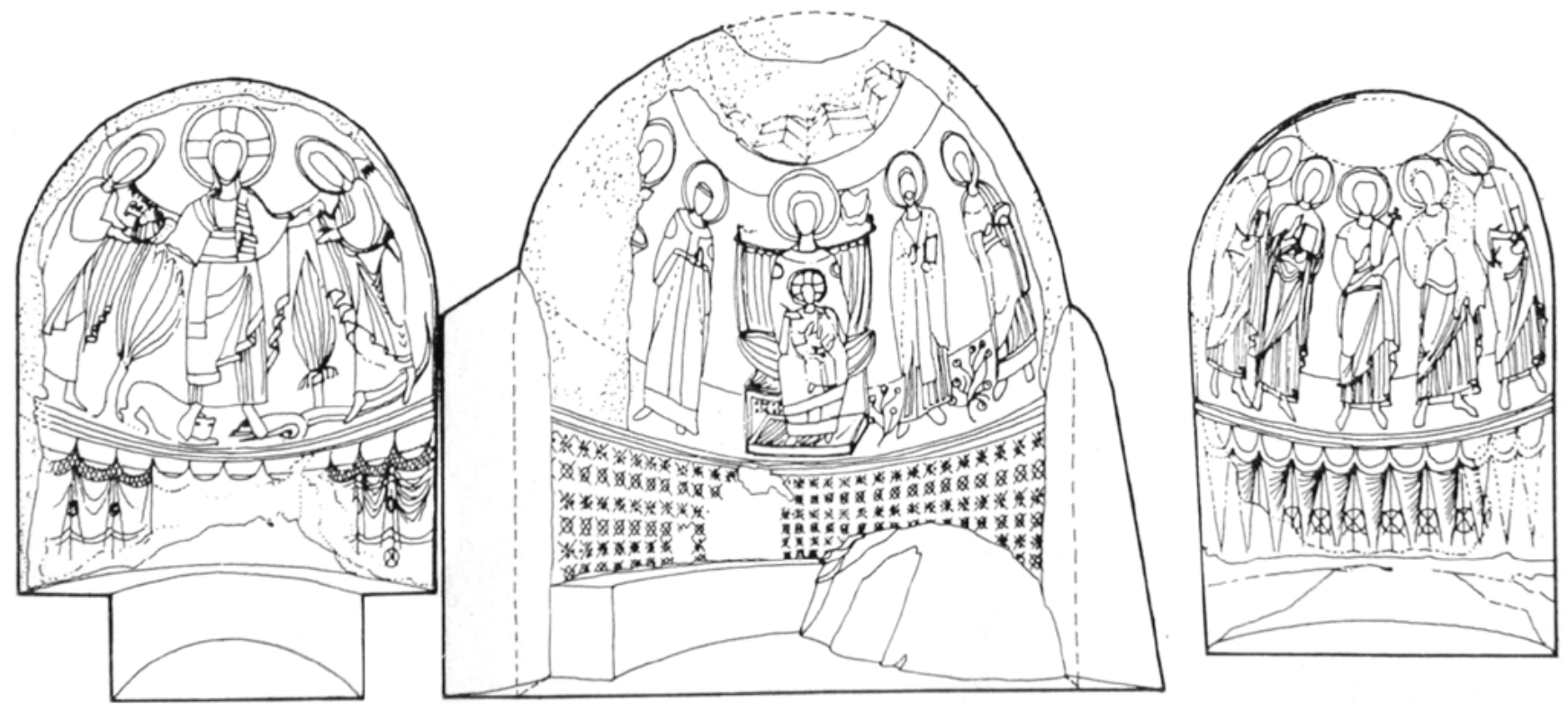

Olevano sul Tusciano, databile alla seconda metà del $x$ secolo o ai primissimi anni dell' $x^{51}$. Lo rivela una serie di coincidenze ivi riscontrabili: l'impaginazione delle figure dell'abside maggiore, con la Vergine in trono fra santi; la presenza del velarium in corrispondenza delle absidiole laterali e non di quella centrale; il motivo del semicerchio radiante in cima alla calotta /Fig. 13/52. Per quanto concerne lo stile, tuttavia, i dipinti di Airola non sono del tutto assimilabili alle pitture di Olevano e di altri contesti campani del tardo x secolo, come il primo strato della Grotta dei Santi a Calvi ${ }^{53}$, i dipinti capuani della chiesa di San Benedetto ${ }^{54}$ e della cripta di San Michele a Corte ${ }^{55}$. In casi come questi le modalità pittoriche appaiono contraddistinte da larghe pennellate, distese su campiture omogenee, senza gradazioni tonali. All'interno della compagine figurativa della chiesa di San Gabriele, invece, i volti meglio conservati - quelli del san Nicola e dei personaggi della Trasfigurazione -, presentano lineamenti meno compassati, più addolciti e sfumati.

La differenza di stile si fa ancora più marcata se si prendono in considerazione gli eleganti esiti formali della decorazione pittorica di Sant'Angelo in Formis, risalente, com'è noto, all'epoca dell'abate Desiderio (1058-1086) ${ }^{56}$. A parte la presenza, anche qui, dell'ornamento a nastro che si diparte da vasi poggiati sopra fusti di colonne, il linguaggio figurativo delle pitture santangiolesi risente, sul piano stilistico, di apporti di chiara origine bizantina, ad Airola del tutto assenti. Basti paragonare le due ver- sioni della Trasfigurazione: quella di Sant'Angelo riproduce il modello greco-orientale più diffuso, senza tende né mano divina e con le rocce aguzze a definire le asperità della montagna ${ }^{57}$.

Né sembra opportuno cercare confronti con la pittura campana più tarda, di fine xI o xII secolo, perché ci si allontanerebbe ancor di più dal linguaggio pittorico adottato nella chiesa di San Gabriele. Una

45 Antonio Battista, Bellarmino Bagatti, La fortezza saracena del Monte Tabor: 609-1212, Gerusalemme 1976.

46 Jules Leroy, Les manuscrits Coptes et Coptes-Arabes illustrés, Parigi 1964, pp. 124-125, tav. 52; Lucy-Anne Hunt, "The commissioning of a late Twelfth century Gospel Book: the frontespieces of Ms Paris, Bibl. Nat. Copte 13", Byzantinische Forschungen, x (1985), pp. 113-139.

47 Sul legame simbolico fra le tende evocate da Pietro durante l'episodio evangelico della Trasfigurazione e i tabernacoli biblici, celebrati nell'ambito della festa ebraica del Sukkot, cfr. Jean Daniélou, Les symboles chrétiens primitifs, Parigi 1961, pp. 9-31,59-60.

48 Hariulf, Chronique de l'abbaye de Saint-Riquier ( $V^{e}$ siècle -1104), a cura di Ferdinand Lot, Paris 1894, p. 63. Un cenno in Louis Réau, Iconographie de l'art chrétien, II, 2, 1957, p. 578, n. 1.

49 Doula Mouriki, The mosaics of Nea Moni on Chios, Atene 1985, I, pp. 56-57, II, figg. 24-31, sp. fig. 26.

50 Dufrenne, "La manifestation divine" (n. 25), p. 192.

51 Rosalba Zuccaro, Gli affreschi nella Grotta di S. Michele ad Olevano sul Tusciano, Roma 1977, p. 110.

52 Ibidem, fig. 138, grafici 11 e 16

53 Simone Piazza, "La Grotta dei Santi e le sue pitture", Rivista dell'Istituto Nazionale d'Archeologia e Storia dell'Arte, LVII (2002), pp. 169-208, sp. pp. 178-186.

54 Speciale/ Torriero Nardone, “Sicut nunc cernitur" (n. 3), pp. 96-100 (per la proposta di anticipazione al x secolo, cfr. Simone Piazza, "Pittura 'beneventana'?" [n. 3], p. 380, n. 71 a p. 383 e fig. 33 a p. 378).

55 Hans Belting, Studien zur beneventanischen (n. 1) pp. 83-91; Simone Piazza, "Pittura 'beneventana'?" (n. 3), p. 382, fig. 32.

56 Fernanda de' Maffei, "Sant'Angelo in Formis i: la data del complesso monastico e il committente nell'ambito del primo romanico campano", Commentari, n. s., xxvII (1976), pp. 143-178.

57 Una fotografia a colori della Trasfigurazione di Sant'Angelo in Formis (dipinta nel registro intermedio della navata sinistra, accanto alla controfacciata) si trova in Gian Marco Jacobitti, La basilica benedettina di Sant'Angelo in Formis, Napoli 1992, tavola pieghevole fuori testo. 

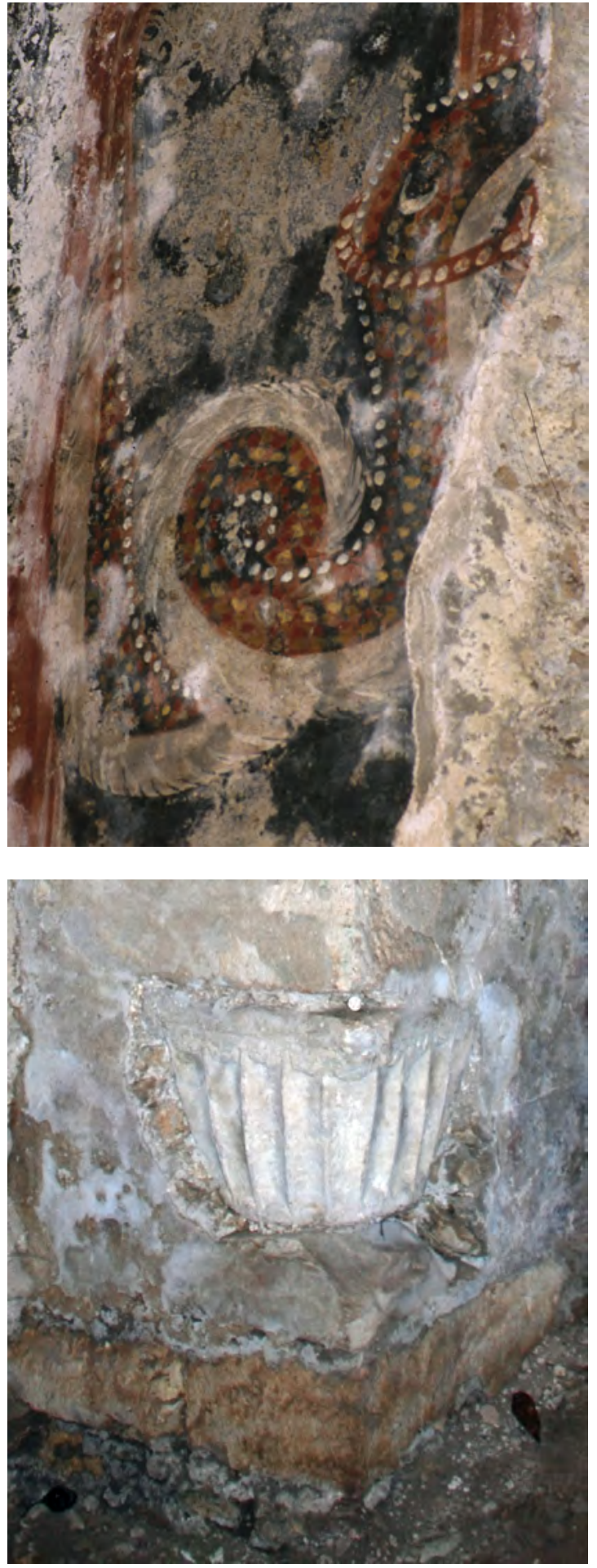

14/ Secondo strato pittorico: il drago della leggenda di San Silvestro, Grotta dei Santi, Calvi, metà dell'xi secolo

15/ Particolare del capitello reimpiegato nel muro della chiesa, chiesa monastica di San Gabriele, Airola, 960-970 datazione entro la prima metà dell'xi secolo sembrerebbe, quindi, la più probabile. Significative, a tal riguardo, appaiono alcune affinità con il secondo strato pittorico della Grotta dei Santi a Calvi, riferibile alla metà circa dell'xi secolo: il drago trafitto dal San Teodoro di Airola, con le spire bicrome, bianche e rosse, percorse da una perlinatura continua, trova un riscontro in una delle immagini della Leggenda di san Silvestro del santuario rupestre del casertano /Fig. 14/58. Anche la serie di linee orizzontali ad andamento ondulato che appare sopra la versione airolese del san Nicola, tracciate per evocare il cielo dell'empireo, incontra una significativa corrispondenza nel primo e nel secondo strato della Grotta dei Santi ${ }^{59}$.

Tra gli anni 960-970, relativi all'epoca di fondazione della chiesa di San Gabriele, e la prima metà dell'xi secolo, arco cronologico al quale sembrerebbe possibile attribuire l'esecuzione delle sue pitture, si apre un divario di diversi decenni. Che la chiesa sia rimasta priva di decorazione durante un periodo così lungo, sembra piuttosto inverosimile. Lo scarto temporale, però, potrebbe acquistare credibilità qualora venisse accertata la presenza di un intonaco precedente - come sembra suggerire l'emergere di tracce di colore al di sotto dello strato della Trasfigurazione -, oppure ipotizzando una ricostruzione della chiesa primitiva, in seguito a danneggiamenti o alla volontà di ampliarne le dimensioni. Se quest' ultima circostanza dovesse essere confermata, assumerebbe maggior senso la presenza di un capitello a scanalature continue, simile ad altri disseminati in area beneventana, riutilizzato nella muratura della parete sinistra della navata centrale, databile forse alla fine del $x$ secolo /Fig. 15/ ${ }^{60}$.

58 Piazza, “La Grotta dei Santi” (n. 53), pp. 204-205, fig. 16, tav. I, n. 9 e 15, II, 26.

59 Ibidem, pp. 183, 191.

60 Il manufatto è inserito nel muro che separa l'abside centrale da quella sinistra: Piazza, "Pittura 'beneventana'?" (n. 3), p. 371, fig. 10. Assai simile è il capitello del portale della cattedrale della vicina Sant'Agata dei Goti, anch'esso di riuso, per il quale Émile Bertaux aveva proposto una datazione alla fine del $x$ secolo: Émile Bertaux, "Per la storia dell'arte nel Napoletano. Sant'Agata dei Goti", Napoli nobilissima, v (1896), pp. 3-9, sp. p. 6. Cfr. Pasquale Raimo, Gli scalpellini di San Benedetto. Koinè culturale, modelli e trasmissioni in epoca altomedievale attraverso la produzione scultorea di due abbazie benedettine nell'Italia centro-meridionale: Montecassino e San Vincenzo al Volturno, tesi di dottorato, Università di Udine, 2012-2013, tutor Valentino Pace, p. 344 e nota 105. Il capitello di Airola è attualmente allo studio di Ulf Schulte-Humberg (docente di architettura alla Eidgenössische Technische Hochschule di Zurigo), che è in procinto di pubblicare una monografia sulla scultura altomedievale nel territorio di Capua. Secondo il collega tedesco un'attribuzione del pezzo di San Gabriele al x secolo risulterebbe la più probabile. 


\section{Summary/Obraz Transfigurace v klášteře svatého Gabriela ad Airola v Beneventu: unikátní prííklad mezi Východem a Západem}

Do korpusu středověké malby v oblasti Beneventa byly v nedávné době přidány malby z klášterního kostela San Gabriele ad Ariola, které byly objeveny za zdmi kláštera Monteoliveto z 18. století. Podle středověkých zdrojů by místo kultu zasvěceného archandělovi mělo být založeno v letech 960-970, $\mathrm{v}$ době Landolfa, prvního arcibiskupa v Beneventu. Dvě papežské buly z dvanáctého století dokazují rozšírení kláštera prostřednictvím série darů. Z kostela svatého Gabriela byly zachovány tř́i apsidy a protilehlá oblast, prostory, v nichž se zachovalo několik zajímavých subjektů náležících $\mathrm{k}$ původní dekoraci: Panna na trůně mezi archanděly a svatými v centrální apsidě; San Teodoro a drak, San Nicola, který zachraňuje stratelatis. V levé lodi se dochovaly další fragmenty; obraz Transfigurace v pravé apsidě, který je předmětem analýzy tohoto př́spěvku.

Pozice scény s námětem evangelia v interiéru jedné apsidy je na základě jejího teofanického charakteru a předchozích setkání více méně známá jak na Východě, tak na Západě. Z obrazového hlediska naopak reprezentuje verze z Airoly unicum, nebot' v popředí vystupují zbytky tří stanů, zřejmě odkaz na ty, které měl zbudovat apoštol Petr pro svého mistra, Eliáše a Mojžíše (Mt. 17,4; Mk 9, 5; Lk, 9,33). Jedná se o velmi sporný ikonografický výběr, nebot' podle výkladu evangelií slova apoštola zůstávají bez povšimnutí, což by mohlo pouka- zovat na nedostatek lidského pochopení božské události. Důvodem jejich zbudování, jak se zdá, má být úmyslná evokace tři svatyní vztyčených na konci 4. století na hoře Tábor na památku míst zjevení Krista a proroků. V některých vzácných středověkých verzích Transfigurace jsou zobrazeny tři malé, zděné budovy, např. na karolinské slonovině, románských hlavicích sloupů, v koptském rukopisu z dvanáctého století. Př́ipad Airoly se však od těchto svědectví liší, nebot věrně a přesně reprodukuje stany a baldachýny (podobně jako svatostánky ze Starého zákona) a ne architektonické stavby. Tato záležitost nachází zajímavou zpětnou vazbu v prrítomnosti ostatků de monte $u b i$ [Christus] transfiguratus est, se zbytky de lignis trium tabernaculorum, což je zaznamenáno v kronice kláštera (8. století) v Saint-Riquier (Centula).

Pozornost se obrací k mimořádnému zobrazení stanů, tento př́íspěvek nabízí úvahy o ikonografii a stylu obrazů v Airole: nejprve ukazuje př́nos byzantského zprostředkování západní figurativní kultuře, následně naopak ukazuje výsledek původního formálního jazyka, který naráží na významnou příbuznost v lokálním kontextu. Na základě takové podoby airolské malby mohou být datované od posledních desetiletí 10. století do první poloviny 11. století, pravděpodobně však blíže k starší dataci. 